\title{
The capillary network of normal and emphysematous human lungs studied by injections of Indian ink
}

\author{
J. ALEXANDER REID ${ }^{1}$ AND B RIAN E. HEARD \\ From the Postgraduate Medical School of London, Du Cane Road, London, W.12
}

In the past few years there has been renewed interest in the pathology of pulmonary emphysema, and the need has arisen to demonstrate the patterns of pulmonary capillaries more clearly. The present paper describes an injection method developed for such purposes using a mixture of black waterproof ink and gelatin. Some preliminary findings in normal and emphysematous lungs are described.

\section{METHOD}

The lung was removed from the chest with care to avoid perforating the pleura. Where there were dense adhesions, extrapleural dissection was carried out. Fresh material was used wherever possible. Blood clots were massaged from the large pulmonary vessels, and a selected cannula of suitable size, made by mounting a grooved rubber bung broad and distally on glass tubing, was tied into the pulmonary artery. Two litres of normal saline was run through the arteries slowly to wash out some of the blood. Mucus was sucked from the bronchi with a narrow glass cannula attached to a filter pump, and the lungs were distended once with air via the bronchi and floated on warm water.

Early trials with dilute mixtures of Raybar cream (50\% barium sulphate) and gelatin failed to fill the capillary bed. Since radio-opacity was not desired, barium sulphate was replaced by ink as follows:

$\begin{array}{lr}\text { Pelican black waterproof drawing ink } & 400 \mathrm{ml} . \\ \text { Distilled water } & 100 \mathrm{ml} . \\ \text { Gelatin } & 45 \mathrm{~g} . \\ \text { Thymol } & 0.5 \mathrm{~g} .\end{array}$

The water was heated to about $80^{\circ} \mathrm{C}$. in a conical flask and the gelatin stirred in until dissolved. The ink and thymol were added to the hot gelatin, and the mixture was filtered through gauze into container $c$ (Fig. 1). It stored well but was usually used immediately. In the apparatus the mixture in container c was heated by hot running water from the tap. Pressure for the injection was supplied as air from container $f$ displaced by water from the raised container $\mathrm{h}$ at a pressure of 60 to $70 \mathrm{~mm}$. $\mathrm{Hg}$ read on the manometer (g). Hot water overflowing down the

1 Present address: Hospital San Juan de Dios, Santiago, Chile channel (d) warmed the tubing (e) and the lung (a) floating in the sink (b).

The injection medium was run in quickly, and sometimes the pulmonary veins were clamped as soon as the ink began to flow out of them, the injection being temporarily interrupted. Once the injection was considered complete the tube (e) was clamped and the lung immersed in cold water and transferred to a refrigerator at $4^{\circ} \mathrm{C}$. overnight to ensure setting of the gelatin.

On the following morning the bronchial tree was injected gently with $15 \%$ formalin, and the lung was left in it to fix for several days. Pressure-fixation

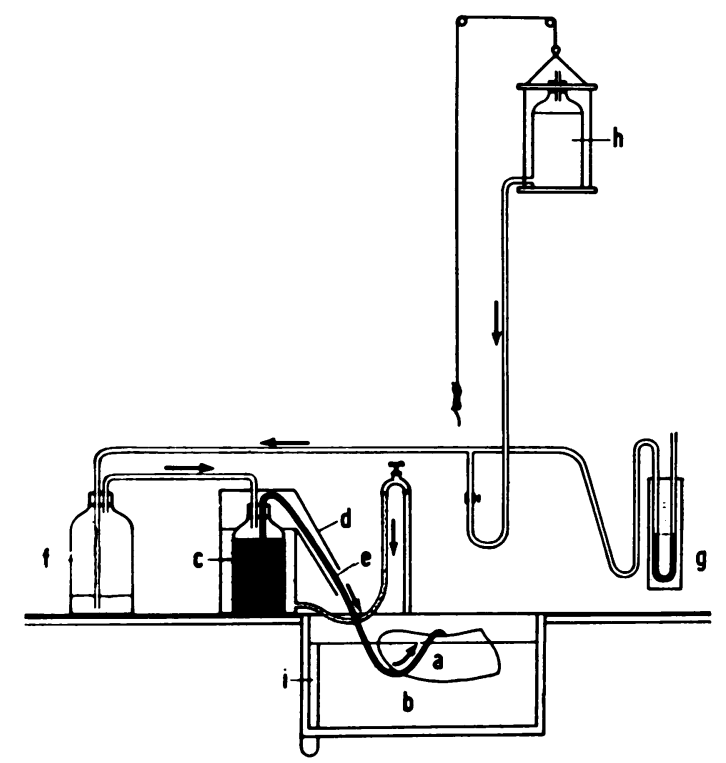

FIG. 1. Diagram of apparatus used to inject pulmonary capillaries. The procedure is described in the text. a, lung; $\mathrm{b}$, hot water in sink; c, Indian ink and gelatin mixture immersed in hot water; $\mathrm{d}$, overflow which keeps conveyor tube to lung (a) warm; e, tube to pulmonary artery; $\mathrm{f}$, pressure jar; g, manometer of mercury; $\mathrm{h}$, water jar to maintain pressure at desired level by raising or lowering; i, overflow of sink. 
(Heard, 1958; 1960) was used in early cases to fix the air spaces evenly for emphysema, but it was found that raising the intra-alveolar pressure to $25-30 \mathrm{~cm}$. of water in the absence of a similar pressure in the pulmonary arteries squeezed some of the injection medium from the capillary bed. It should be noted that this is not a contra-indication to the use of pressure-fixation in studying other aspects of emphysema. Antero-posterior slices were cut from the lateral surface of the lung, using a ham knife supported on rails, and some of these were impregnated with barium sulphate (Heard. 1958; 1960).

Our original plan was to study injected pulmonary capillaries in barium sulphate-treated slices under the dissecting microscope (Figs. 2, 3, and 4). The density of the capillaries in the alveolar walls was so great. however, that it was found necessary to cut frozen sections, 250 to 500 ". thick, of selected blocks of tissue to study fine detail. Both the above procedures were followed in each case. Frozen sections were cut in Gurr's gum syrup and mounted in Canada balsam. (D.P.X. mountant was abandoned because it shrank severely on drying.) Some sections were stained lightly with neutral red to advantage. Ordinary 5 ". sections were often prepared also.

Blocks were taken routinely from a point $4 \mathrm{~cm}$. from the apex and $8 \mathrm{~cm}$. from the base of the lung at right angles to large pulmonary arteries. Other blocks were selected from emphysematous areas detected in the slices after barium sulphate impregnation.

The injection material sometimes escaped into and filled alveoli, rendering areas of lung unsuitable for examination. Rarely, however, was the whole lung so affected.

\section{FINDINGS}

Over the last year we have injected 16 human $\frac{\bar{C}}{\overline{0}}$ lungs, some normal and others showing varying $\frac{\rho}{\Phi}$ degrees of emphysema. Information has been $\varrho$ obtained on the normal capillary bed, and some preliminary findings in moderate emphysema are $\overrightarrow{0}$ described.

The cut surface of a normal lung after ink $\overrightarrow{\vec{\omega}}$ injection is shown in Fig. 2. Close inspection of the photograph reveals that the dark grey appear- $\bar{x}$ ance is due to an enormous number of closely- $\vec{\infty}$ packed capillaries, especially in alveoli. The capil- $\omega$ laries of the non-respiratory bronchioles are less 0 dense and separated by more pale tissue. In the acinus partly illustrated in Figs. 3 and 4 the later orders of respiratory bronchioles are darker than $\vec{c}$ the earlier orders because they carry more alveoli. $\mathbb{D}$

Ordinary 5-7 $\mu$ thick paraffin sections show $\frac{0}{\Phi}$ closely-packed capillaries in the alveolar walls $\frac{\sqrt{3}}{3}$ (Fig. 5) but do not give a clear view of their distribution. A great improvement in visualization of the fine vessels was achieved by the use of thicker sections (Fig. 6). The photograph does not convey the full stereoscopic effect of the prepar-8 ation, for the vessels appear here as silhouettes. This method of sectioning was used for most of $\overline{0}$ the detail of the present study.

A remarkable system of intercommunicating $\stackrel{\frac{\Omega}{\odot}}{\varrho}$ vesiels was seen in the normal lung, especially $\overrightarrow{\hat{O}}$ around bronchi. The injection material ran into 3 pulmonary and bronchial arteries and veins. Since

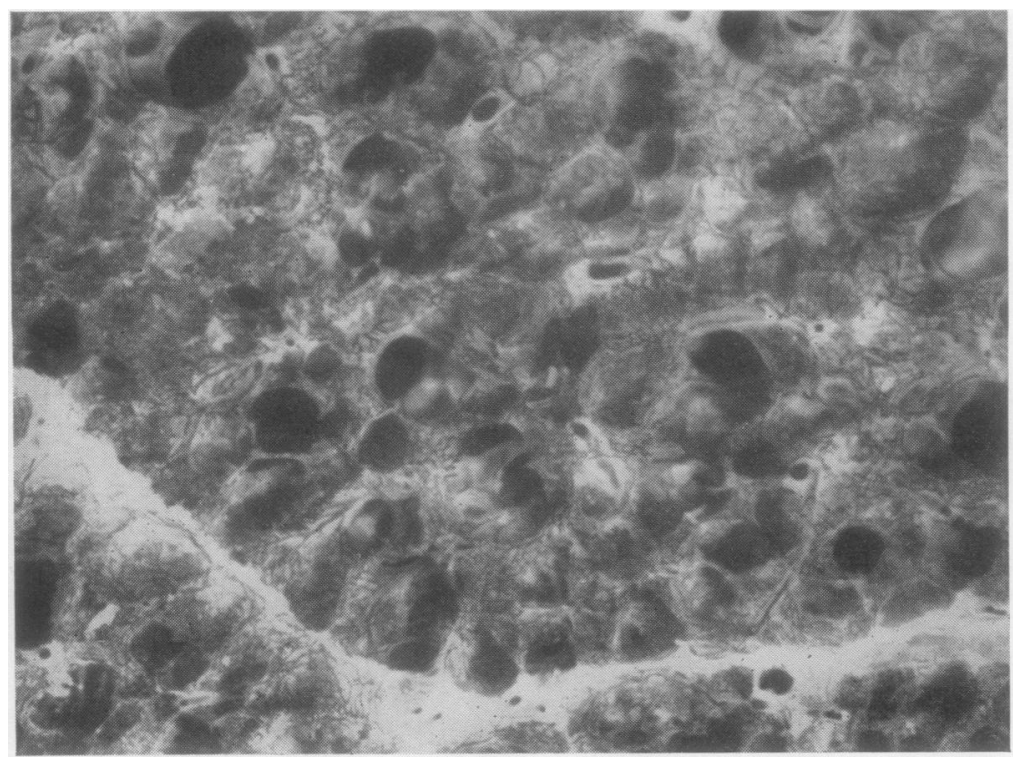

FIG. 2. Appearance of cut surfaceo of lung after injection of capillaries and barium sulphate impregnation. The centre of the secondary lobule is in the middle of the photograph $\mathrm{N}$ and the periphery is demarcated by the whitened septum along the요 lower margin. The vessels are toow closely set to be studied in detailo in this way $(\times 26)$. 


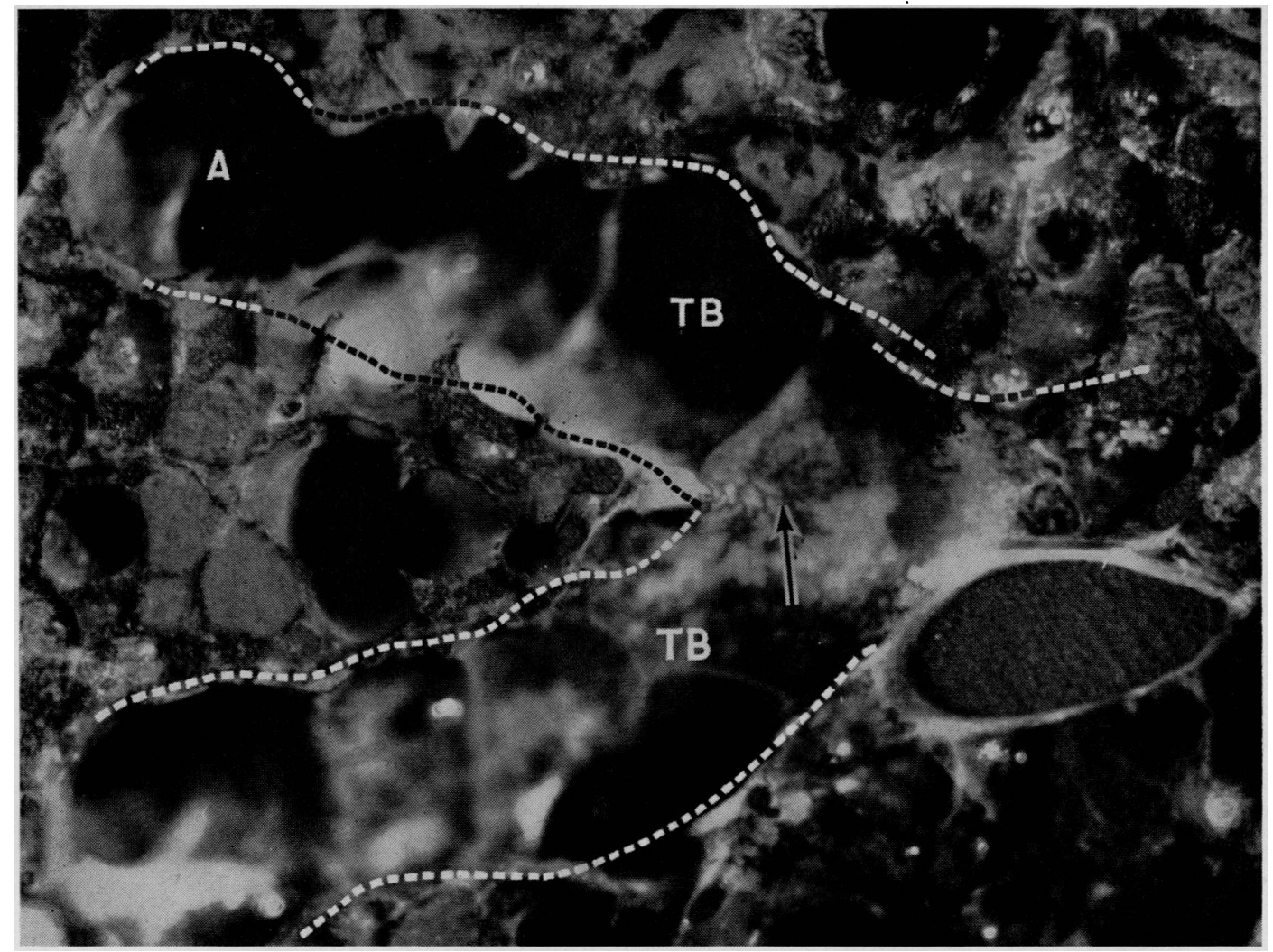

FIG. 3. Surface view of the point where two terminal bronchioles originate. In the mucosa the injected network is not so fine (arrow) as in the alveoli (see Fig. 4). This photograph overlaps with Fig. 4. TB=Terminal bronchiole; $A=$ bronchiole repeated in Fig. 4 ( $\times 38)$.

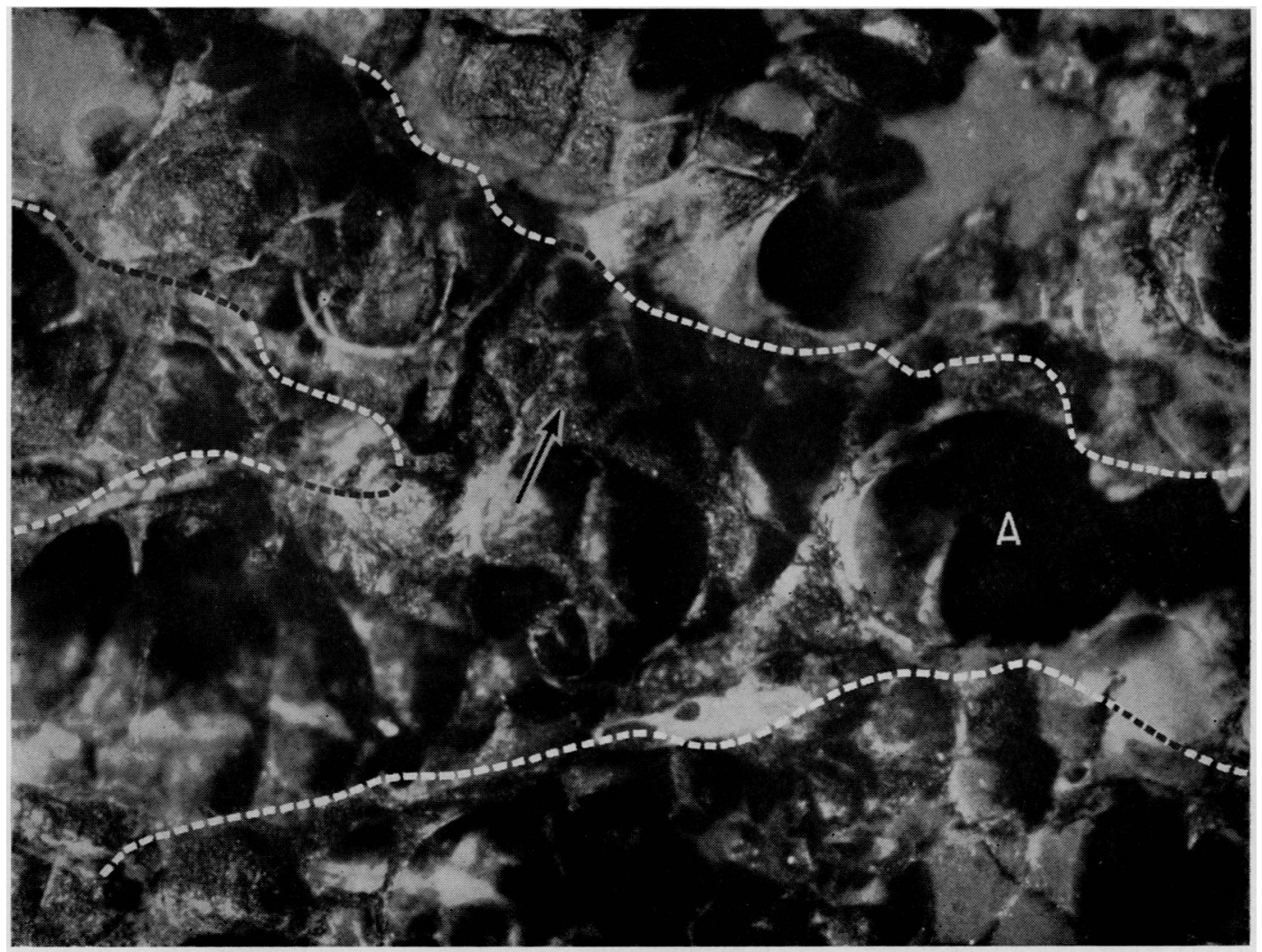

FIG. 4. The upper bronchiole A in Fig. 3 is on the right, and it divides into a pair of respiratory bronchioles. Note how dark the alveoli of these bronchioles are internally (arrow), due to the dense network of injected capillaries $(\times 38)$. 


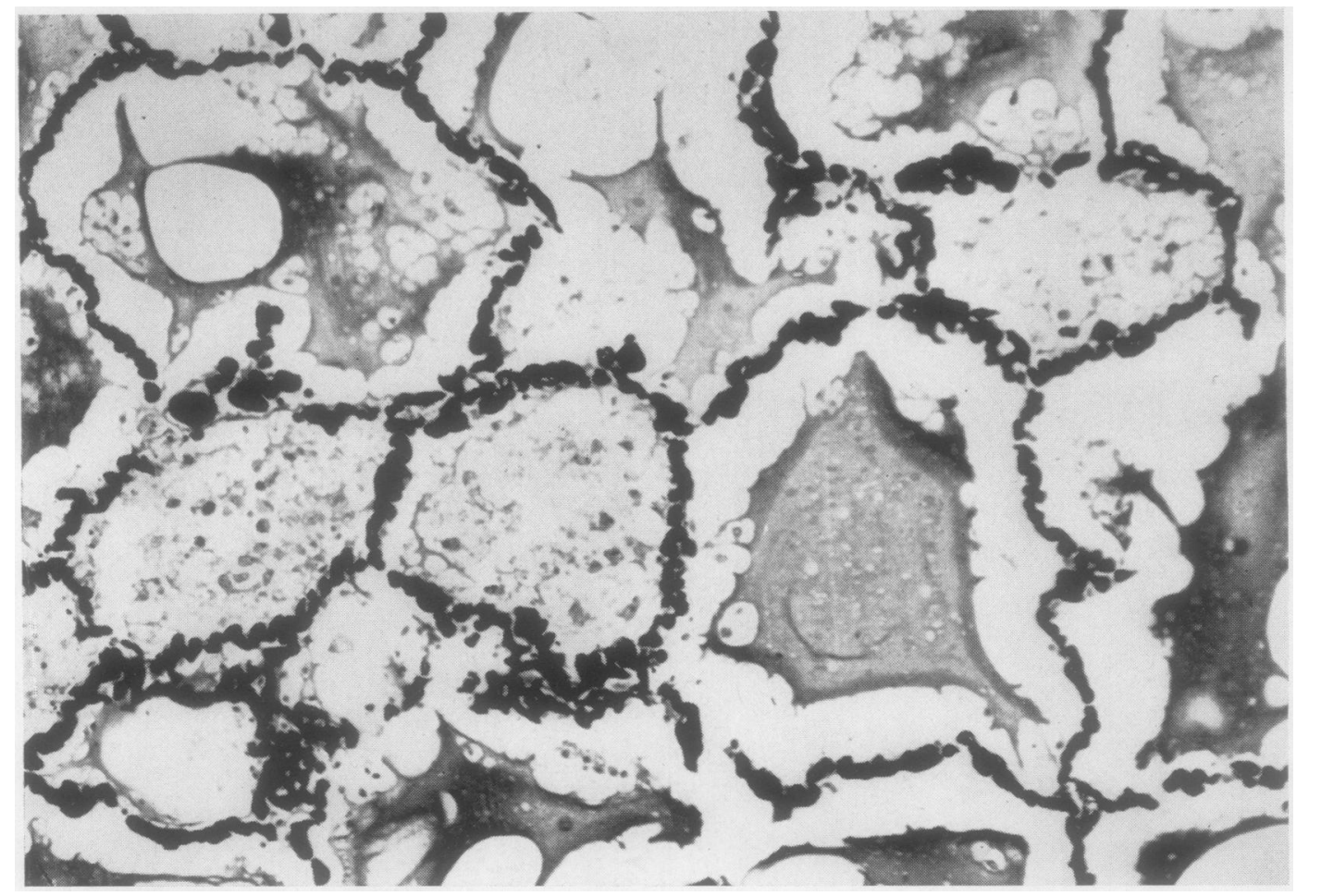

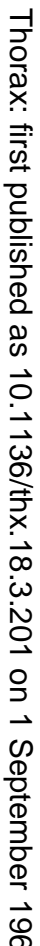

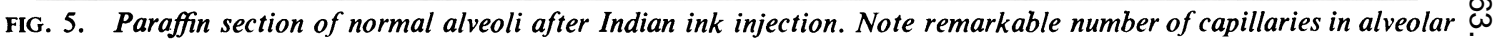
walls and how they appear to bulge in the lumina $(\times 100)$.

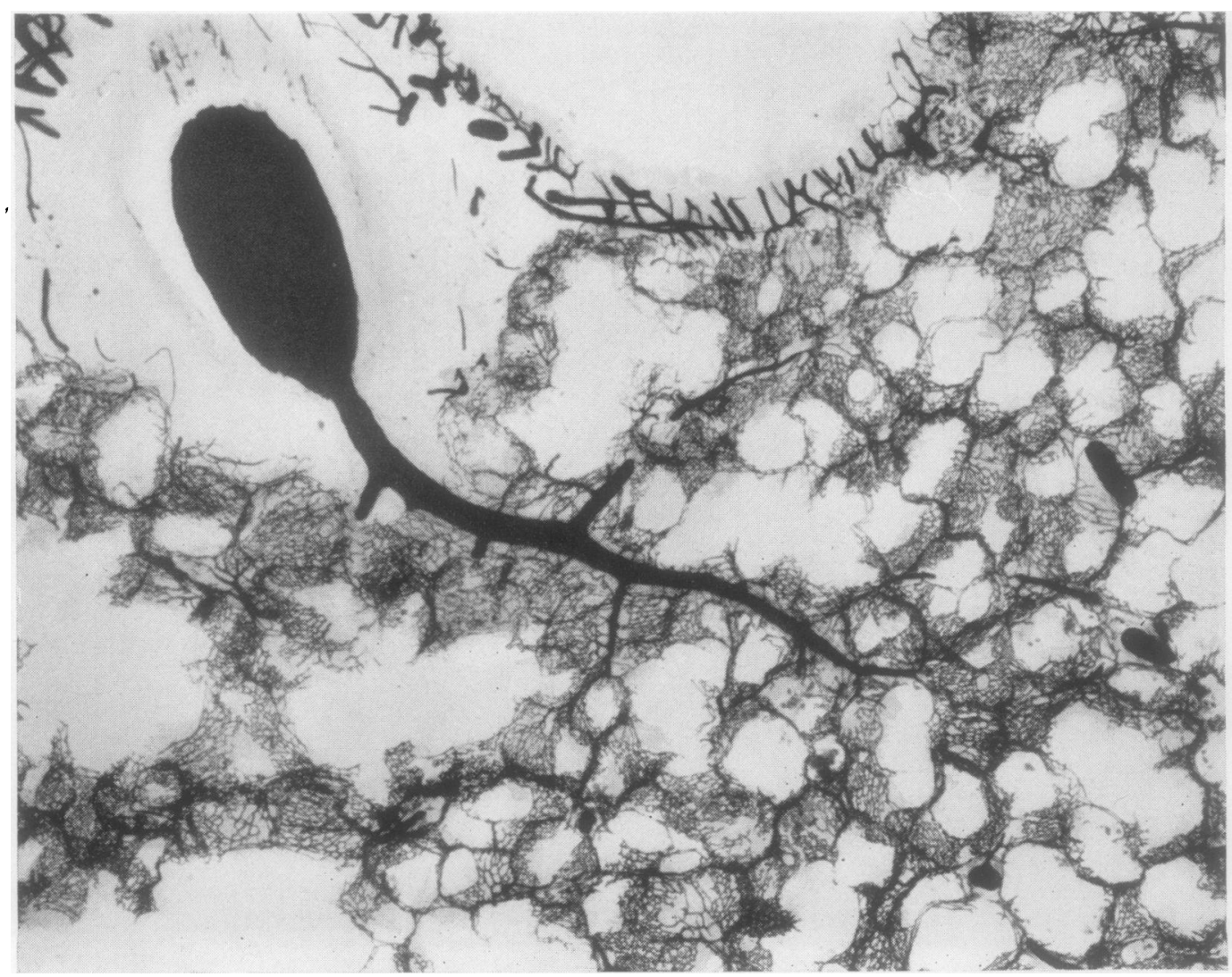

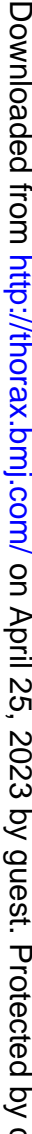

FIG. 6. The pulmonary artery (top left corner), which is $600 \mu$ internal diameter, gives off a branch which has small and $\bigcirc$ large branches supplying adjacent and distant alveoli, respectively. The internal diameter of the branch at its origin is $100 \mu$. Note how rapidly it tapers. Plexuses of the bronchiole at the top of the picture communicate freely with adjacent $\underline{0}$ alveolar networks $(\times 33)$. 
all vessels were black they were identified by their size and shape and their position in the secondary lobule. Normal pulmonary arteries entered the centres of the secondary lobules after accompanying bronchi and bronchioles through the lung. Venules drained the peripheries of the lobules to veins lying in the septa. These anatomical points allowed identification of many, but not all, vessels. Pulmonary arteries were normally similar in diameter to the bronchi they accompanied when they were medium-sized, but near the lobule they were smaller in comparison.

The pulmonary artery in the upper left corner of Fig. 6 is about $600 \mu(0.6 \mathrm{~mm}$.) internally and it accompanies a bronchus (top centre). The $100 \mu$ branch arising from its lower right-hand region gives off an enormous number of side branches as soon as it leaves the parent vessel. The largest branches, which are arterioles up to $30 \mu$ in internal diameter, in turn throw off many side branches of a similar pattern to supply more distal alveoli. The small side arterioles, $15 \mu$ or less internally, supply the immediately adjacent alveolar capillary network. The main branch tapers rapidly. The large side arterioles run in tissue at the corners of adjacent alveolar walls, sending out frequent radial branches to supply the alveolar capillary network.

The very small side branches joined the capillary network immediately as in Fig. 7. In that photograph the large $75 \mu$ parent pulmonary arteriole, crossing the field obliquely, gives off a small $15 \mu$ arteriolar branch (A). After a short course through the wall of the parent vessel the branch (A) divides into three or more smaller arterioles which branch as they join the capillary network.

The alveolar capillaries intercommunicated to form a network of polygonal spaces with about six lengths of capillary around each space hole. The capillaries are $5 \mu$ across in Fig. 7 , but other authors have found them wider (see Discussion). The spaces between them vary greatly in size, being, on an average, $20 \mu$ across but often down to $5 \mu$ in this preparation. Occasionally a larger round or oval space was seen in normal lung and presumed to be a pore of Cohn. Holes were more common and larger in emphysema (see below).

In the walls of respiratory bronchioles the capillaries had a larger mesh, average $15 \times 40 \mu$ (centre of Fig. 8), than those of alveoli (edge of Fig. 8), and the oval shape of the meshes gave them directional axes. They were thus easily distinguished from the smaller, rounder alveolar meshes. The capillary and bronchiolar types of network merged almost imperceptibly, for the capillaries themselves were similar in calibre.

Occasionally in a normal area of lung the network was interrupted by a round or oval hole which we presumed to be a pore of Cohn. There was usually a circular capillary around the edge of the hole which communicated freely with capillaries all round and was sometimes slightly larger than these. The holes were sometimes more frequent and larger in emphysematous areas (Fig. 9) where they could measure over $100 \mu$ in diameter. More observations will be carried out to establish by our method the upper limit of size of normal pores of Cohn. The presence of numerous holes in emphysematous areas supported the description of fenestration in emphysema known over 100 years ago (e.g., Rainey, 1848 ; Waters, 1862). The possibility that many of the holes arose as tears was borne out by the occasional finding of minute, blind-ended, short capillaries on the inner aspect of the surrounding ring capillary.

One pattern of capillaries in a patch of emphysema from a left upper lobe is illustrated in Fig. 10. The large vessel in the right upper corner is a pulmonary venule and it collects blood from an abnormal capillary bed. The original alveolar capillaries are scarce (arrow), and most of the finest remaining network is bronchiolar in type with a wide mesh and directional axes. The slightly thicker branches coursing through the lung are small arterioles and venules. These normally lie at the junctions of adjacent alveolar walls and are somewhat obscured by the capillary networks (Figs. 6, 12, and 13). In Fig. 10, perhaps they are slightly thicker than their normal counterparts. In some places the bronchiolar capillaries are also becoming thinned out. Many of the emphysematous holes are ringed by a marginal capillary. While there is a drastic reduction in the alveolar capillary bed which could cut down gaseous exchange, the remaining vessels still appear capable of carrying a good flow of blood from artery to vein. Incidentally, this is a localized patch of diffuse emphysema from a left upper lobe. An adjacent secondary lobule was normal.

Where emphysema was more severe than in the last example and all that remained of the parenchyma was strands crossing large spaces, the injection showed that in the core of each strand was a large artery or arteriole, usually patent (Fig. 11). In the residual tissue around the artery were a few smaller arterioles or a trace of a bronchiolar or capillary network. An occasional web of tissue showed more of a network persisting but the original respiratory pattern was almost 


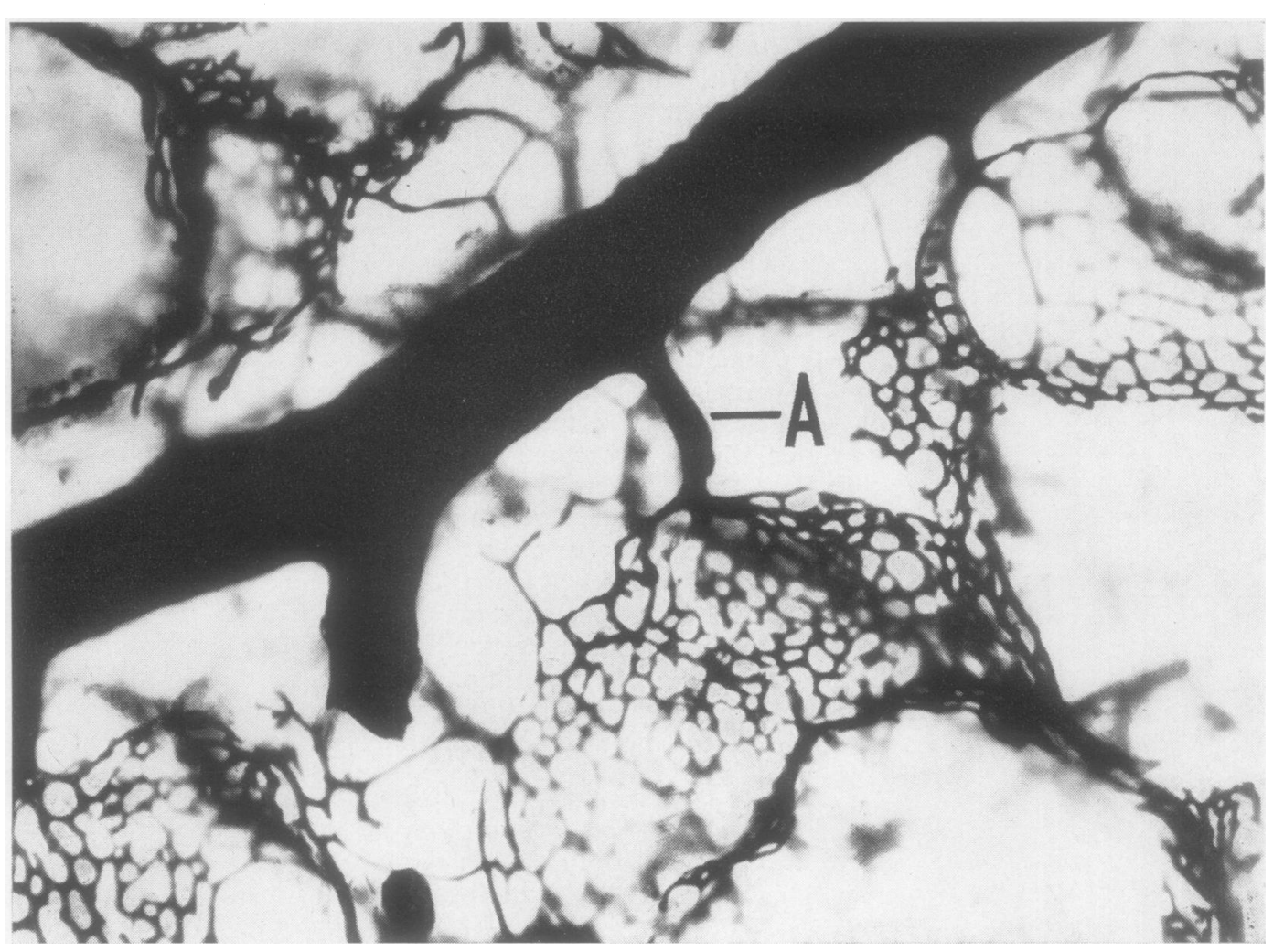

FIG. 7. Higher magnification of a pulmonary arteriole and branches. The large arteriole crossing the field obliquely is $75 \mu$ in diameter, internally. In the centre of the photograph a branch $15 \mu$ in diameter $(A)$ passes down to join a capillary network via three short vessels of intermediate size $(\times 200)$.

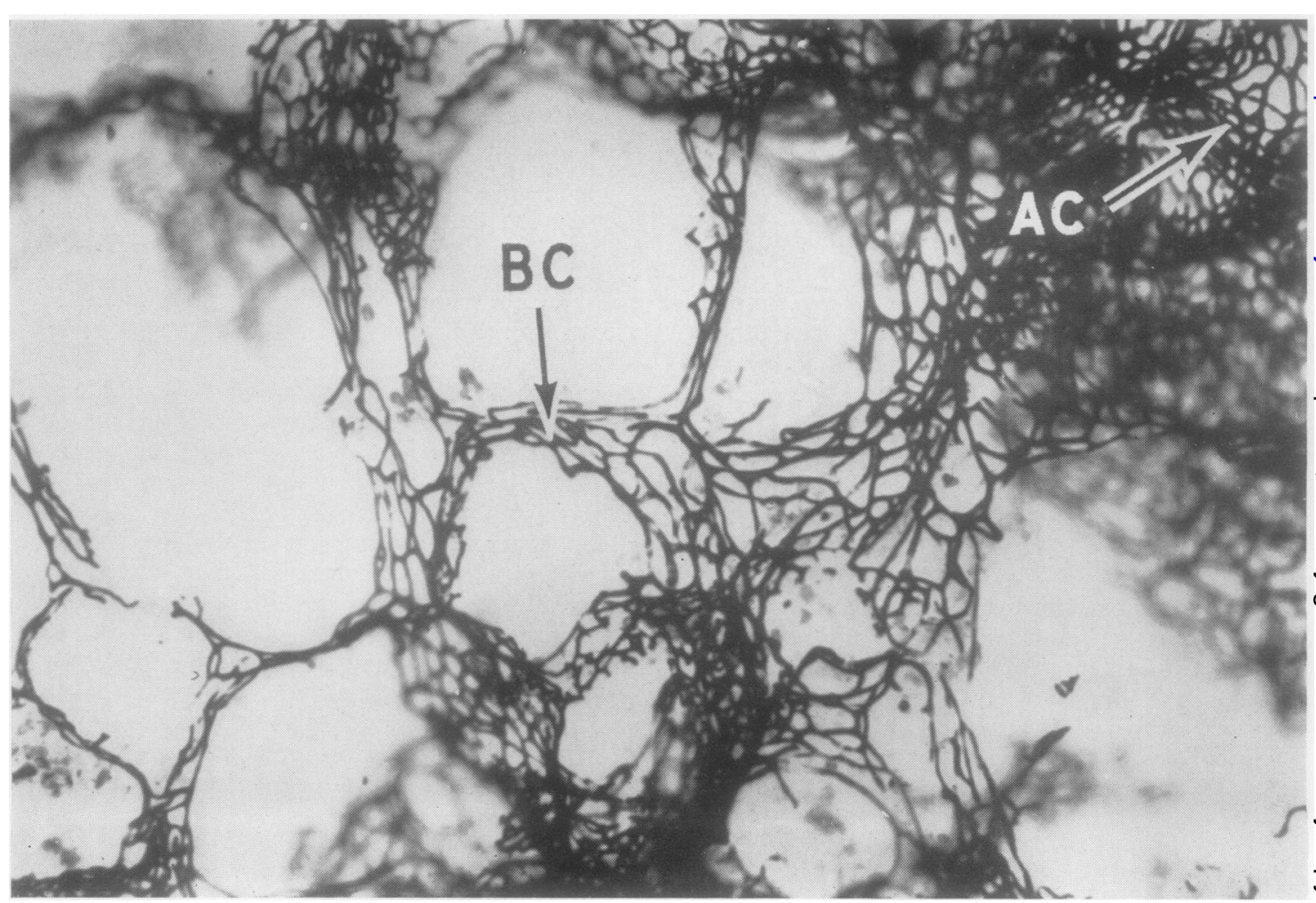

FIG. 8. The walls of respiratory bronchioles in the centre show a capillary network with a wider mesh than alveoli (see this in top right corner). The oval shape of the meshes gives them direction in contrast to alveolar capillaries (top right corner) which are more rounded. $B C=$ Bronchiolar capillaries; $A C=$ alveolar capillaries $(\times 134)$. 


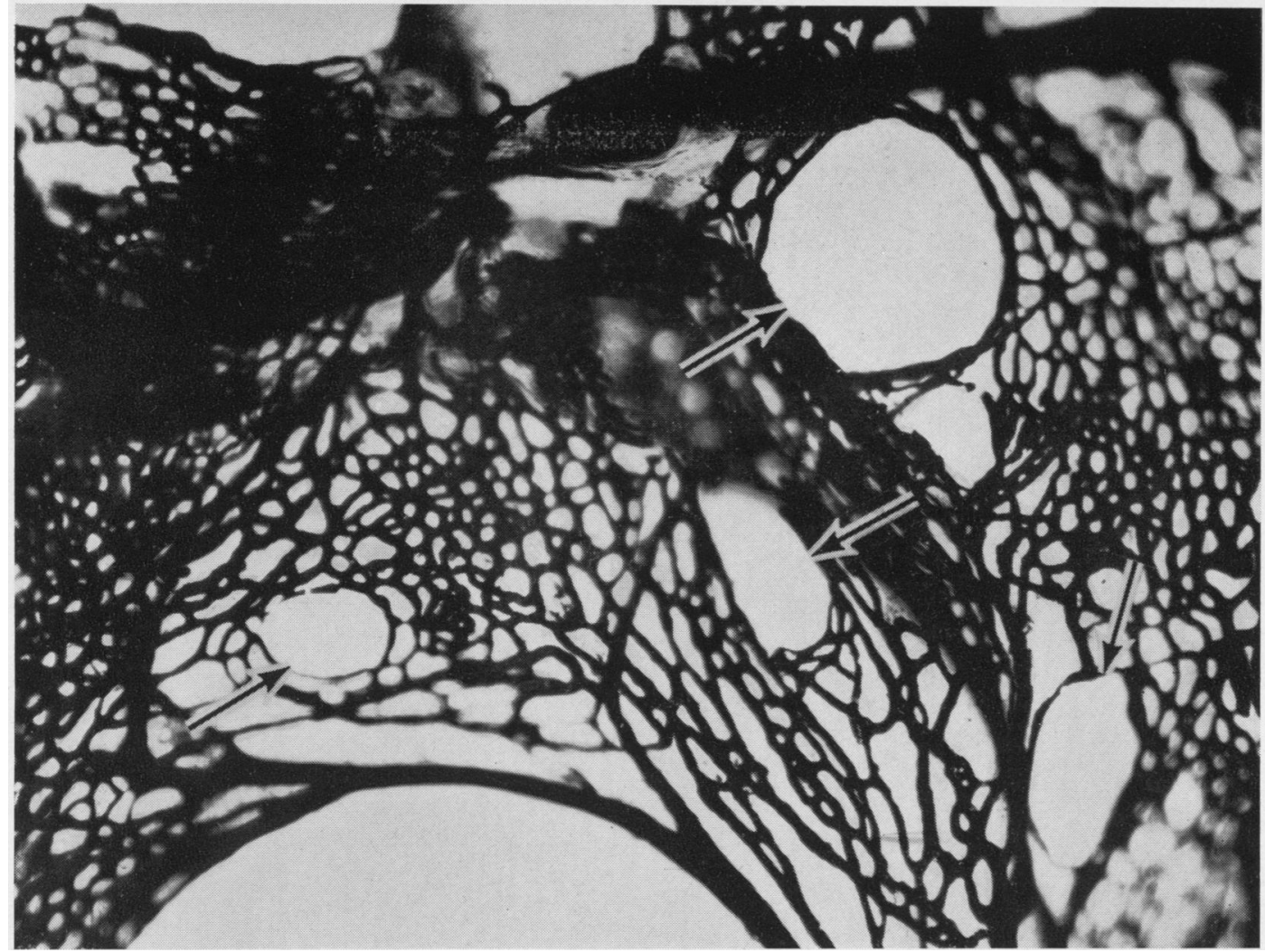

FIG.9. Emphysematous lung showing holes (arrows) in capillary network, each bordered by a continuous capillary $(\times 175)$.

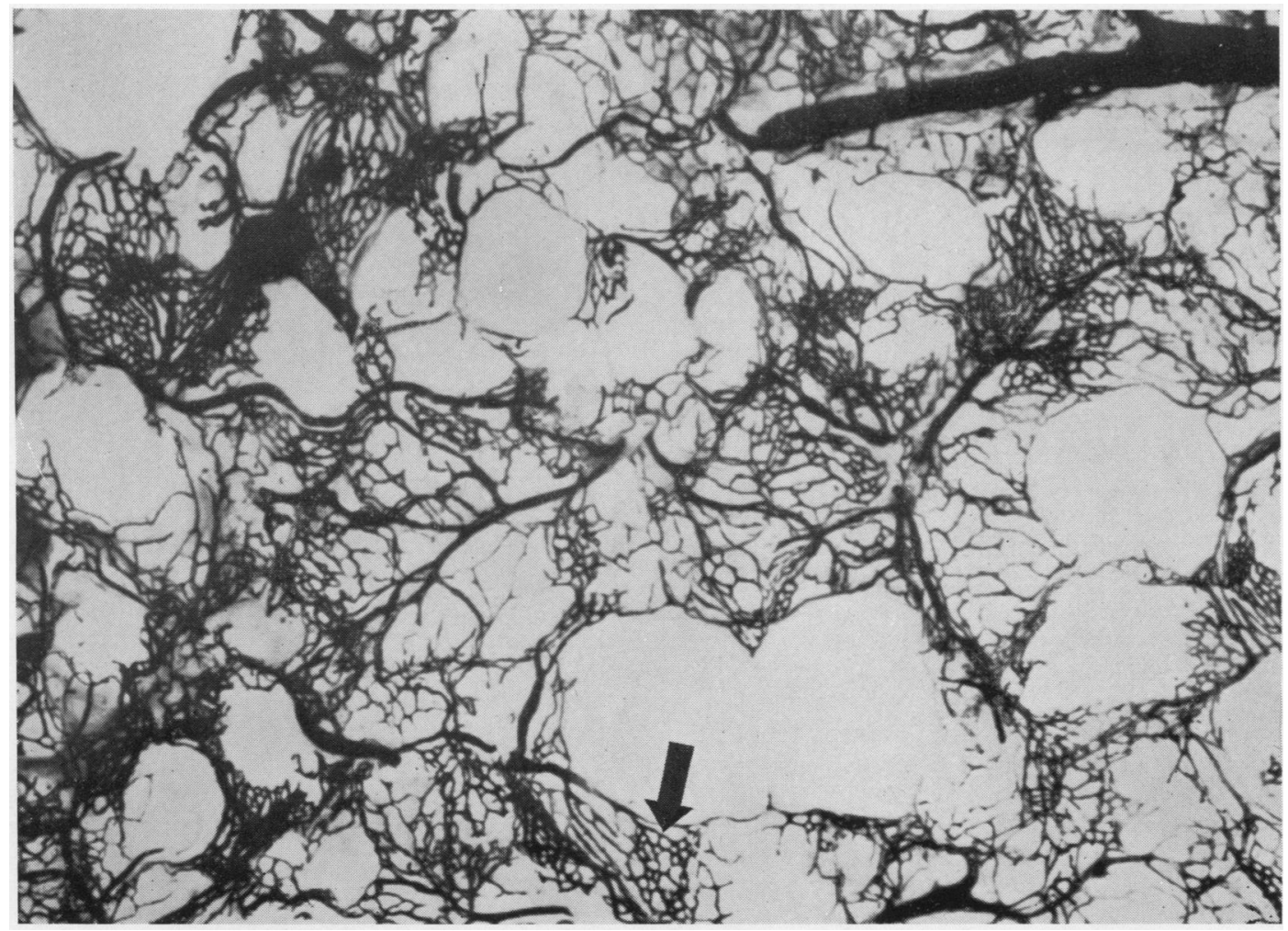

FIG. 10. Emphysematous lung showing scanty alveolar networks (arrow), moderately well preserved bronchiolar networks, and persisting arterioles and venules. The large vessel (top right corner) is a venule $(\times 50)$. 


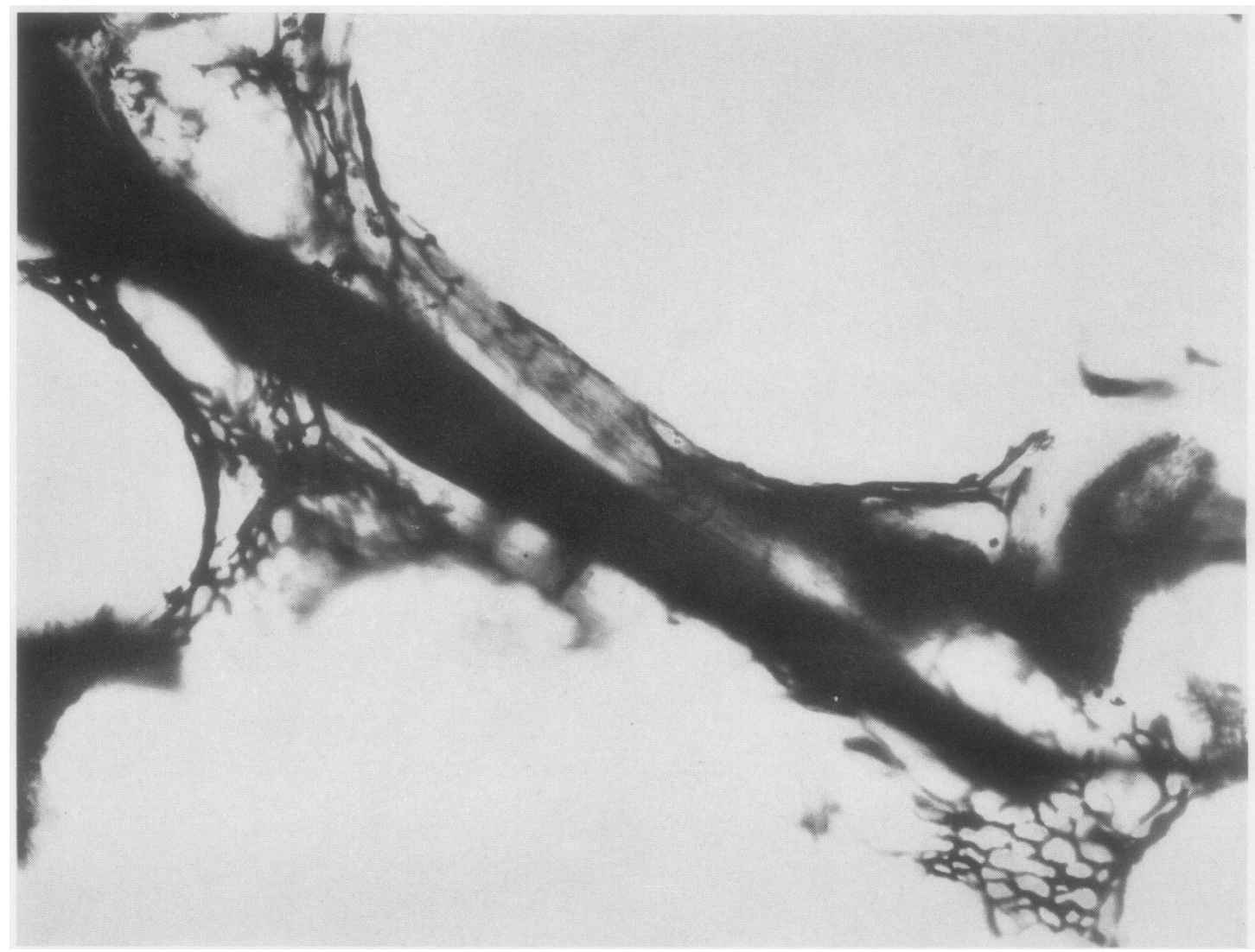

FIG. 11. Emphysematous lung showing reduction in side branches to an arteriole passing through an emphysematous area, but a widely patent lumen $(\times 145)$.

destroyed. In advanced centrilobular emphysema the side branches of the arteries or arterioles accompanying the affected proximal respiratory bronchioles are obliterated but the large vessels survive. These course through the area as isolated strands stripped of side branches but still patent and supplying the peripheral surviving networks of the lobule. When the latter capillaries are destroyed one might suspect that surviving arterioles could carry arterial blood straight into venules and veins without communicating with alveolar or bronchiolar capillaries. Further work is needed to be sure that such communications do exist in emphysema and to discover their size.

Figs. 12 and 13 show networks from the upper and lower lobes, respectively, of a normal lung. They were photographed at the same magnification and show no obvious differences, contrary to the views of others, e.g., Krahl (1959). There is no emphysema. The scattered networks with a wider mesh in the lower lobe are bronchiolar, and some of the same-sized mesh can be seen also in the upper lobe. Note the occasional hole (pore of Cohn) in both lobes. The significance of similar patterns in the two lobes is discussed later.

\section{DISCUSSION}

The chief points of interest to us in the present $\mathrm{N}$ studies were the enormous number of side $N$ branches to normal pulmonary arterioles, the $N$ pores of Cohn in normal lungs, fenestration in $\frac{\omega}{\sigma}$ emphysema, and the survival of many arterioles and venules when the capillary bed was lost in emphysema.

We have shown how arterioles accompanying respiratory bronchioles and alveolar ducts give off very many side branches, large and small. Knisely $\underset{\mathbb{D}}{\mathbb{D}}$ (1960) described this pattern in living animals and $\frac{\mathrm{P}}{\mathrm{D}}$ contrasted it with the "simple dichotomous branch- 


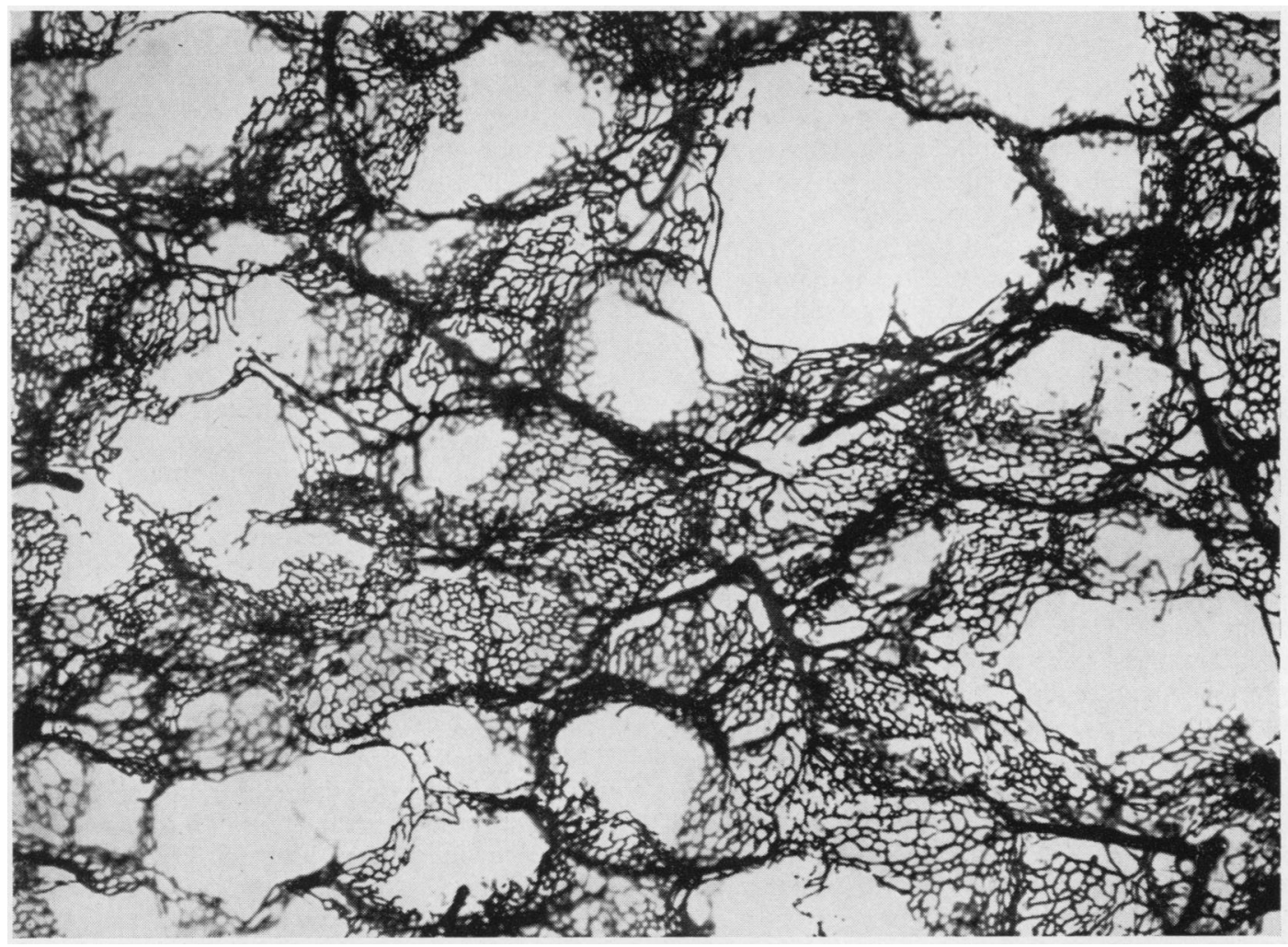

FIG. 12. Normal upper lobe showing similar pattern to normal lower lobe in Fig. 13. Both from same lung $(\times 80)$.

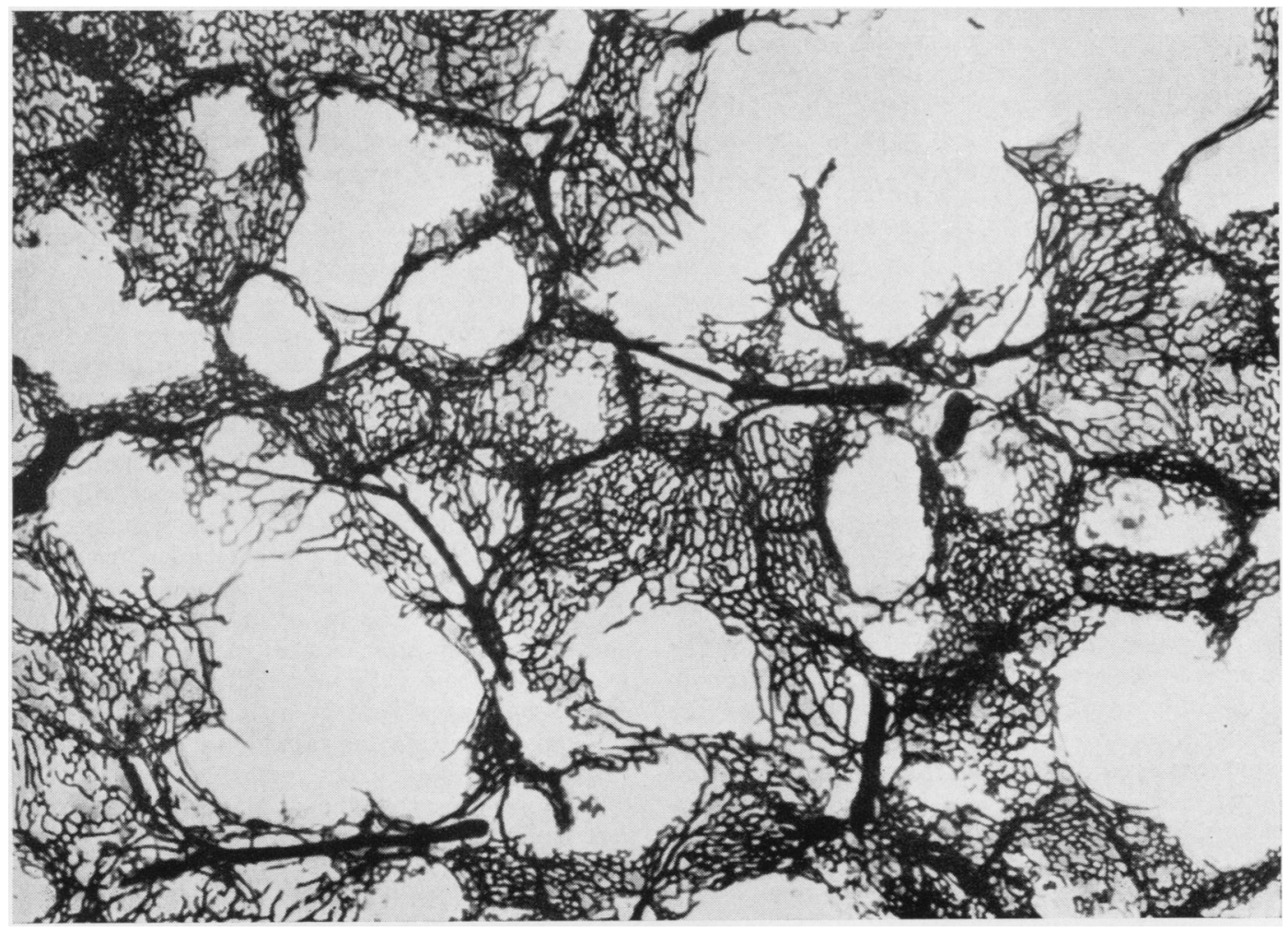

FIG. 13. Normal lower lobe showing similar pattern to normal upper looe in Fig. $12(\times 80)$. 
ing of systemic arterioles supplying capillary beds'. Krahl (1959) injected Indian ink into the right ventricle of the beating heart of a mouse and also found this pattern. It appears to be typical of mammals. Incidentally, judging by Krahl's photographs (his Fig. 10), the alveolar capillary network in the mouse appears slightly simpler than in man, having smaller collections of vessels and fewer meshes. His intercapillary distances cannot be compared with those in our preparations, however, because our air spaces are more fully distended and the walls more spread out.

Miller (1947) stated that the bronchial arteries could be followed as far as the first order of respiratory bronchioles where alveoli appeared, and there they joined an arterial plexus in the fibrous layer of the bronchiole. He found that small branches penetrated the muscle coat and formed a network of capillaries, the long axis of which corresponded to the long axis of the bronchiole. Venous radicals arose from that and formed another plexus with an irregular rectangular mesh of thin vessels still on the inner side of the muscle coat. This drained through short branches in the muscle coat to form another plexus on the outside, composed of larger vessels, and from this arose one of the sources of origin of the pulmonary vein.

The significance of the many side branches running out from pulmonary arteries and arterioles is that if the alveolar walls supplied by the side branches atrophy or are destroyed, a good blood flow may still pass through that region in the parent vessels. In centrilobular emphysema, for example, loss of respiratory tissue from the centres of the lobules strips the arteries and arterioles of the central zone of their branches to alveolar capillary networks, but that does not prevent blood from flowing in the larger vessels and to the alveoli in the peripheral paraseptal zone. Dunnill (1961) has made the interesting suggestion that pulmonary hypertension may be caused by air pressure in the lesion compressing the surviving vessels.

When a secondary lobule shows more extensive loss of alveolar capillary networks, as in diffuse (panacinar) emphysema, surviving arterioles and venules may still convey blood through that lobule although their side branches have vanished. The process may be similar to what we have seen in centrilobular emphysema where pruning of the side branches does not affect the patency of the parent vessels. Preliminary findings suggest that the ends of arterioles and venules in emphysematous lung are connected by broadened capil- laries, but further studies on this are in progress at the moment. Spain (1959) studied capillaries in emphysematous lungs that were hyperaemic or congested so that the vessels were more easily seen. There was diminution in the number of capillaries in many parts of the emphysematous walls, and their distribution was irregular. Relatively more pre-capillary arterioles and small arteries were seen.

The persistence of arterioles and bronchiolar networks when alveolar networks are lost would be compatible with the growing amount of clinical evidence that patients with advanced pulmonary emphysema do not necessarily have hypertrophy of the right ventricle. Mounsey, Ritzmann, Selverstone, Briscoe, and McLemore (1952) showed that pulmonary hypertension in emphysema may be reversible, being high during attacks of acute bronchial infection but falling to normal between attacks.

A striking feature of our preparations was the way in which vessels intercommunicated on such a large scale in normal lungs. This was especially notable around the bronchi and bronchioles where bronchial-type networks and adjacent alveolar networks communicated freely. Weibel (1959) has carried out injection studies in the human lung and suggests that anastomoses normally occur between arteries and veins, pulmonary or bronchial, in any combination. Liebow (1962, personal communication) has observed wide communications between arteries and between veins but not between arteries and veins in normal lungs.

Staub (1961) has described a method for examining the pulmonary capillaries of animals in a state comparable to that in life. $\mathrm{He}$ opens the chest of an anaesthetized cat and freezes a lung very rapidly by inundating it with up to three litres of liquid propane cooled to $-180^{\circ} \mathrm{C}$. with liquid nitrogen. This procedure stops the capillary blood flow almost instantly in the outermost part of the lung, and his findings are of great physiological interest. For example, he has viewed vessels down to $50 \mu$ in diameter and noted that when $N$ a cat is ventilated with $100 \%$ oxygen, the blood in the frozen pulmonary arterioles (even quite large ones) is wholly or partially oxygenated (bright red) whereas in a cat breathing room air the pulmonary arteriolar blood is dark red. That observation raises the possibility that the arterioles we observe surviving in an emphysematous area of lung may still be capable of carrying out a degree of gaseous exchange.

Staub claims that the pulmonary capillaries do not bulge into the lumina of air spaces in his 
preparations. We find this surprising since in some of our preparations of deep alveolar networks the capillaries were only about 3 to $5 \mu$ in diameter and still bulged into the air spaces (see Fig. 5). The calibre of the human pulmonary capillaries under normal living conditions is not known. Knisely (1960) described some valuable observations made on the surfaces and edges of living animal lungs using quartz-rod transillumination and a dissecting microscope. He gave figures of 12 to $14 \mu$ for the diameter of pulmonary capillaries of living animals, a little wider than systemic capillaries. Intercapillary distances are commonly claimed to be sometimes less than the width of the capillaries themselves. In our preparations the alveolar intercapillary distances were very variable, averaging $20 \mu$ but as low as $5 \mu$, and greater where capillaries were interrupted by the very rounded holes of the pores of Cohn. Von Hayek (1953) put the diameters of pulmonary capillaries (? human) at 10 to $12 \mu$, as judged by fixation in situ by perfusion at approximately the pulmonary blood pressure. He found between four and 12 capillary meshes from pre-capillary to post-capillary with a consequent variation in the length of the capillary course of the blood (only about $60 \mu$ through four capillary meshes but about $250 \mu$ through 12 meshes). The diameters of capillaries in our preparations varied according to the quantity of injection material retained, and that was affected by the viscosity and temperature of the injection material, the unusual pressures each side of the capillary wall, and the fact that the vessel walls were dead and toneless.

Orsós (1936) used a silver impregnation technique for pulmonary capillaries. He found emphysematous changes in the lungs in the first year of life, namely enlargement and an increase of pores, stretching of the inter-alveolar partitions, etc. In the adult he found, especially in the upper parts of the lungs, widening of alveoli and a progressive decrease in density of the capillaries. Many capillaries were obliterated and others widened so that in places the regular polygonal capillary network was replaced by a more sparse wide-meshed capillary system of wide lumina. Along with this was an increase in elastic and collagen. He demonstrated these differences between the lobes with two photographs, one from each lobe, taken at the same magnification. Krahl (1959) states that the capillary networks vary widely in their density, depending upon their location in the lung. We have included Figs. 12 and 13 to show that in the absence of emphysema the two lobes had the same pattern of capillaries.
Since emphysema is common in the upper parts of the upper lobes in the general population, comparison of the vasculature of the lobes must be undertaken only after great care has been taken to exclude emphysema (Heard, 1958; 1960). Respiratory bronchioles more than $0.7 \mathrm{~mm}$. across in the adult lung (excluding attached alveoli) indicate emphysema, and isolated strands of tissue passing through air spaces indicate emphysema with destruction.

Most pulmonary vascular studies in emphysema have concerned the larger vessels and anastomoses between bronchial and pulmonary circulations. Liebow (1959) summarized the changes in larger vessels, viz., medial hyperplasia of the muscular arteries, sometimes extreme, and atheromatous changes in the larger arteries with associated thrombosis. The venous side of the pulmonary circulation is greatly expanded in emphysema (Liebow, 1953); the bronchial veins double in diameter and may allow blood to travel in either direction between the atria. Cudkowicz and Armstrong (1953) described obliterative changes in the bronchial arteries in emphysema. Marchand, Gilroy, and Wilson (1950) described widespread macroscopic bronchopulmonary arterial anastomoses in emphysema which must have been due to dilatation of existing anastomoses. McLean (1958) put forward a theory that sclerosis of the small arteries (adjoining terminal and respiratory bronchioles) in emphysema resulted from the organization of thrombi, this thrombosis being precipitated by the cause of the inflammation of the adjoining air passages.

\section{SUMMARY}

The capillaries of human lungs at necropsy have been studied by an injection procedure using a mixture of gelatin and black waterproof ink.

The capillary networks were similar in upper and lower lobes in the absence of emphysema.

Alveolar capillary networks had small and rounded meshes. Bronchiolar capillary networks had larger oval meshes.

Occasional pores of Cohn were seen with a ringlike capillary.

In emphysema 'fenestrae' were seen, with surrounding ring-like capillaries.

The remarkably numerous side branches to arterioles are illustrated. It is pointed out that when these side branches are lost in emphysema a good blood flow may still be possible through surviving arterioles. That would be compatible with the clinical observations of others that the 
pulmonary artery pressure in emphysema may be normal between attacks of infection.

We wish to thank Professor C. V. Harrison for his advice and Mr. W. Brackenbury for the photographs. One of us (J. A. R.) was in receipt of a grant from the British Council.

\section{REFERENCES}

Cudkowicz, L., and Armstrong, J. B. (1953). The bronchial arteries in pulmonary emphysema. Thorax, $8,46$.

Dunnill, M. S. (1961). An assessment of the anatomical factor in cor pulmonale in emphysema. J. clin. Path., 14, 246.

Heard, B. E. (1958). A pathological study of emphysema of the

lungs with chronic bronchitis. Thorax, 13, 136 . (1960). Pathology of pulmonary emphy

von Hayek, H. (1953). Die menschliche Lunge. Springer, Berlin. Trans. (1960) Krahl, V. E., Hafner Publishing Co., New York.

Knisely, W. H. (1960). In vivo architecture of blood vessels supplying and draining alveoli. Amer. Rev. resp. Dis., 81, 735.

Krahl, V. E. (1959). Microscopic anatomy of the lungs. Ibid., 80, No. 1, Pt. 2, p. 24.
Liebow, A. A. (1953). The bronchopulmonary venous collateral circulation with special reference to emphysema. Amer. J. Path. 29,251 .

(1959). Pulmonary emphysema with special reference to vascular $\overline{\bar{S}}$

changes. Amer. Rev. resp. Dis., 80, No. 1, Pt. 2 , p. 67 .
McLean, K. H. (1958). The significance of pulmonary vascular $\overparen{D}$ changes in emphysema. Aust. Ann. Med., 7, 69

Marchand, P., Gilroy, J. C., and Wilson, V. H. (1950). An anatomical study of the bronchial vascular system and its variations in $\mathcal{C}$ disease. Thorax, 5, 207.

Miller, W. S. (1947). The Lung, 2nd ed., p. 74. Thomas, Springfield, $\vec{\ominus}$ Illinois.

Mounsey, J. P. D., Ritzmann, L. W., Selverstone, N. J., Briscoe, = W. A., and McLemore, G. A. (1952). Circulatory changes in $\omega$

severe pulmonary emphysema. Brit. Heart J., 14, 153 .
Orsós, F. (1936). Die Gerüstsysteme der Lunge und deren physio- $\underset{\overrightarrow{7}}{\overrightarrow{7}}$ logische und pathologische Bedeutung. Beitr. klin. Tuberk., 87, $\vec{x}$ 568.

Rainey, G. (1848). On the minute anatomy of the emphysematous $\vec{\infty}$

lung. Med. $-C^{n}$ ir. Trans. (Lond.), 31, 297.
Spain, D. M. (1959). In Pulmonary Circulation. An International $\omega$ Symposium, 1958. Ed. Adams, W. R., and Veith, I., p. 99. Grune is and Stratton, New York and London. Staub, N.C. (1961). Microcirculation of the lung utilizing very rapid

Waters, A. T. H. (1862). Researches on the Nature, Pathology and Treatment of Emphysema of the Lungs, and its Relations with other Diseases of the Chest. Churchill, London.

Weibel, E. (1959). Die Blutgefässanastomosen in der menschlichen (D) Lunge. Z. Zellforsch., 50, 653 . 